\title{
TRATAMENTUL MINIM-INVAZIV AL HIDRONEFROZEI CONGENITALE LA COPIL
}

\author{
Anna Kadar ${ }^{1,2}$, Lorena Vatrăa ${ }^{1}$, Marcel Oancea ${ }^{1}$ \\ ${ }^{1}$ Clinica de Chirurgie Pediatrică, Spitalul Clinic de Urgență pentru Copii „,M.S. Curie“, \\ Bucureşti \\ ${ }^{2}$ Universitatea de Medicină şi Farmacie „, Carol Davila“, Bucureşti
}

\begin{abstract}
REZUMAT
Introducere. Tratamentul minim-invaziv al hidronefrozei congenitale la copil rămâne un subiect controversat, atât prin prisma momentului şi criteriilor operatorii, cât şi prin adresarea tehnicilor laparoscopice la sugar şi copilul mic.

Material şi metodă. Studiul îşi propune analiza criteriilor operatorii ale unui lot de pacienți operați laparoscopic pentru hidronefroză congenitală în perioada 2007-2015, în cadrul Clinicii de Chirurgie Pediatrică a Spitalului Clinic de Urgență pentru Copii „M.S. Curie“, Bucureşti.

Rezultate. În lotul studiat, cel mai frecvent criteriu utilizat pentru indicația chirurgicală este dilatația bazinetului peste $3 \mathrm{~cm}$, urmat de alterarea (sub 50\%) a grosimii parenchimului, alterarea funcționalității renale sub $40 \%$ şi în final criteriile simptomatice - infecțiile urinare şi durerile colicative lombare. Atât dilatația bazinetului cât şi grosimea parenchimului renal se corelează cu funcția renală, corelația fiind mai puternică pentru grosimea parenchimului renal. Sugarii sub 1 an şi sub 10 kg au fost reprezentați în proporție semnificativă (17,5\% şi respectiv 22,5\%)

Concluzii. Vârsta mică (sub 1 an) şi greutatea redusă (sub 10 kg) a pacientului nu constituie un motiv de temporizare a tratamentului chirurgical. Pielectazia nu este specifică sindromului de joncțiune pielo-ureterală, poate apărea în absența unei obstrucții şi nu prezintă întotdeauna o corelație puternică cu alterarea funcției renale. Elementele de bază în stabilirea conduitei terapeutice sunt: amploarea restructurărilor parenchimatoase renale, gradul afectării funcției renale şi simptomatologia clinică. Tratamentul laparoscopic este o soluție chirurgicală care întruneşte toate avantajele minim-invazivității, aplicabilă copiilor şi sugarilor, indiferent de vârstă şi greutate.
\end{abstract}

Cuvinte cheie: PUJO, hidronefroză congenitală, pieloplastie laparoscopică

\section{INTRODUCERE}

Indicațiile tratamentului chirurgical în hidronefroza congenitală la copil - sindrom de joncțiune pielo-ureterală (PUJO), în ciuda numeroaselor dezbateri, reprezintă în continuare un subiect controversat, atât din punct de vedere al momentului operator, cât şi din punct de vedere al criteriilor utilizate în stabilirea indicației chirurgicale. Deşi aflat pe un trend ascendent, tratamentul laparoscopic al PUJO, considerat tratament de elecție la copiii mari şi adulţi, este încă în curs de acceptare ca soluție minim-invazivă la sugar şi copilul mic.

Lucrarea îşi propune analiza criteriilor operatorii şi a caracteristicilor de vârstă şi greutate ale unui lot de pacienți operați de manieră laparoscopică.

\section{MATERIAL ŞI METODĂ}

Articolul reprezintă un studiu retrospectiv efectuat in cadrul Clinicii de Chirurgie Pediatrică a Spitalului Clinic de Urgență pentru Copii „Marie Curie“ Bucureşti, pe un lot de pacienţi operaţi consecutiv laparoscopic pentru hidronefroză congenitală (PUJO), în intervalul 2007-2015.

Variabilele colectate din foile de observaţie şi din cadrul programului Hospital Manager sunt:

- vârsta şi greutatea;

- prezența durerilor lombare colicative în absența infectiiilor urinare;

- episoadele de infecții urinare în antecedente;

- diametrul antero-posterior al bazinetului (DAP); 
- dimensiunile parenchimului renal, atât în valoare absolută cât şi în valoare relativă (raportată la valoarea normală corespunzătoare vârstei pacientului);

- valoarea indicelui pelvis/cortex;

- funcția renală relativă determinată prin scintigrafie renală DTPA.

Am luat în considerare următoarele 5 criterii pentru indicația chirurgicală laparoscopică şi am analizat frecvența şi distribuția acestora în lotul studiat:

\begin{tabular}{|l|l|l|}
\hline Simptomatologie & C1 & $\begin{array}{l}\text { prezența durerilor colicative lombare } \\
\text { în absența infecției urinare }\end{array}$ \\
\cline { 2 - 3 } & C2 & $\begin{array}{l}\text { prezența episoadelor de infecție } \\
\text { urinară în antecedente }\end{array}$ \\
\hline $\begin{array}{l}\text { Alterarea } \\
\text { morfologiei } \\
\text { renale }\end{array}$ & C3 & $\begin{array}{l}\text { diametrul antero-posterior al } \\
\text { bazinetului cu valori > 3 cm }\end{array}$ \\
\cline { 2 - 3 } & C4 & $\begin{array}{l}\text { grosimea parenchimului renal sub } \\
\text { 50\% din valoarea normală }\end{array}$ \\
\hline $\begin{array}{l}\text { Alterarea funcției } \\
\text { renale }\end{array}$ & C5 & $\begin{array}{l}\text { funcție renală relativă sub 40\%; } \\
\text { deteriorarea progresivă funcției } \\
\text { renale }\end{array}$ \\
\hline
\end{tabular}

Rezultatele au fost analizate prin prisma distribuției şi frecvenței criteriilor operatorii şi a caracteristicilor pacienților din lotul studiat.

\section{REZULTATE}

Lotul de studiu este compus din 34 de pacienți cu hidronefroză unilaterală şi 3 pacienți cu hidronefroză bilaterală operați consecutiv de manieră minim-invazivă.

Pacienții au avut la momentul operației vârste între 3 luni şi 18 ani, cu o medie de 6,7 ani, greutatea acestora fiind între 6 şi $90 \mathrm{~kg}$ (cu o medie de $27,9 \mathrm{~kg}$ ). Distribuția pacienților pe grupe de vârstă şi intervale de greutate este prezentată în Tabelele 1 şi 2.

TABELUL 1. Distribuția numerică şi procentuală pe grupe de vârstă a pacienților

\begin{tabular}{|c|c|c|}
\hline Grupa de vârstă & Număr pacienți & $\begin{array}{c}\text { Distribuție procentuală } \\
\text { (\%) }\end{array}$ \\
\hline $0-1$ an & 7 & 17,5 \\
\hline $1-5$ ani & 12 & 30 \\
\hline $5-10$ ani & 9 & 22,5 \\
\hline $10-18$ ani & 12 & 30 \\
\hline
\end{tabular}

TABELUL 2. Distribuția numerică şi procentuală pe intervale de greutate a pacienților

\begin{tabular}{|c|c|c|}
\hline Interval de greutate & Număr pacienți & $\begin{array}{c}\text { Distribuție } \\
\text { procentuală (\%) }\end{array}$ \\
\hline $0-10 \mathrm{~kg}$ & 9 & 22,5 \\
\hline $10-20 \mathrm{~kg}$ & 12 & 30 \\
\hline$>20 \mathrm{~kg}$ & 19 & 47,5 \\
\hline
\end{tabular}

\section{Simptomatologie}

Corespunzător celor 40 de unități renale operate, am înregistrat prezența durerilor colicative lombare în absența episoadelor de infecție urinară la 13 pacienți $(32,5 \%)$. Infecția urinară a fost consemnată la 14 pacienți (35\%).

\section{Alterarea morfologiei renale}

Analizând morfologia renală, diametrul anteroposterior al bazinetului a înregistrat valori între 14 şi $64 \mathrm{~mm}$, cu o medie de $31,11 \mathrm{~mm}$. Diametrul $>3$ cm a fost regăsit la 29 de unităţi renale operate, reprezentând o incidență de $72,5 \%$. La 13 pacienţi s-a înregistrat o variabilitate mare a dimensiunilor bazinetului la diferite examinări, cu valori mult crescute în contextul hidratării, asociate cu episoade colicative lombare. Un element constant a fost aspectul balonizat, convex al calicelor renale.

TABELUL 3. Incidența dilatației semnificative a bazinetului (DAP)

\begin{tabular}{|l|c|c|}
\hline Diametru bazinet & Număr (n) & Procente (\%) \\
\hline Peste $3 \mathrm{~cm}$ & 29 & 72,5 \\
\hline Sub $3 \mathrm{~cm}$ & 11 & 27,5 \\
\hline
\end{tabular}

Parenchimul renal în valoare absolută prezintă, în contextul variabilității vârstei pacienților, o relevanță redusă. S-au înregistrat valori între $2,5 \mathrm{~mm}$ şi $15 \mathrm{~mm}$. Pentru o interpretare corectă a afectării parenchimului renal, am utilizat valoarea relativă a grosimii acestuia, raportând valoarea patologică la valoarea normală corespunzătoare vârstei pacienților; aceste valori normale au fost culese din normograme care prezintă dimensiunile renale corespunzătoare vârstei copiilor. Raportarea la valorile ipotetic normale este preferabilă față de raportarea la dimensiunile rinichiului controlateral, datorită fenomenelor de hipertrofie renală controlaterală compensatorie, care tind să supraestimeze distrucția parenchimatoasă (1).

Valorile relative ale parenchimului renal au fost astfel între $25 \%$ şi $95 \%$. 26 de unităţi renale au prezentat afectare semnificativă a morfologiei renale cu valori relative ale grosimii parenchimului renal sub 50\%, reprezentând $65 \%$ din totalul subiecților. Am considerat o afectare renală nesemnificativă o valoare relativă a parenchimului renal de peste $80 \%$, valoare pe care am întâlnit-o la 11 pacienți, respectiv într-un procent de $27,5 \%$.

TABELUL 4. Incidența distrucției parenchimului renal

\begin{tabular}{|c|c|c|}
\hline $\begin{array}{c}\text { Alterarea relativă a } \\
\text { parenchimului renal }\end{array}$ & Număr (n) & Procente (\%) \\
\hline Sub 50\% & 26 & 65 \\
\hline $50-80 \%$ & 3 & 7,5 \\
\hline Peste $80 \%$ & 11 & 27,5 \\
\hline
\end{tabular}


Indicele pelvis/cortex a fost calculat ca raportul dintre diametrul antero-posterior al bazinetului şi grosimea parenchimului, reprezentând un index care cuprinde ambele caracteristici renale (2). La lotul studiat am înregistrat o valoare medie de 6,34, cu extreme de 2,13 şi 25,6.

\section{Alterarea funcției renale}

Funcţionalitatea renală a fost analizată în urma examenului scintigrafic cu DTPA, urmărindu-se aspectul curbei, precum şi funcționalitatea renală relativă. Examenul scintigrafic a fost efectuat la 33 de unităţi renale, pe $82,5 \%$ dintre subiecți. Toți pacienții supuşi interventiei chirurgicale au prezentat o curbă de tip obstructiv, 11 pacienți prezentând răspuns pozitiv la administrarea de Furosemid.

Valoarea funcției renale comparative a fost între 7 şi $49 \%$; valori peste $40 \%$ au fost înregistrate la 13 pacienți: 11 pacienți care au prezentat obstrucție incompletă prin vas polar şi 2 pacienți cu hidronefroză bilaterală. 20 de pacienți au prezentat funcții renale relative sub $40 \%$ şi deteriorare funcțională progresivă.

TABELUL 5. Afectarea funcționalității renale

\begin{tabular}{|l|c|c|}
\hline Funcționalitate relativă renală & Număr (n) & Procente (\%) \\
\hline Sub 40\% & 20 & 60 \\
\hline Peste 40\% & 13 & 40 \\
\hline
\end{tabular}

Analizând criteriile indicaţiei chirurgicale, găsim cel mai frecvent întâlnit criteriu pentru indicația chirurgicală ca fiind valoarea diametrului antero-posterior cu valori peste $3 \mathrm{~cm}$, urmat de alterarea sub $50 \%$ a grosimii parenchimului, alterarea funcției renale sub $40 \%$ şi în final criteriile simptomatice infecțiile urinare şi durerile colicative lombare (Fig. 1).

Analizând statistic pacienții care au prezentat reducerea semnificativă a funcției renale, se con- stată o corelație semnificativă statistic a disfuncționalităţii cu alterarea morfologiei renale (grosime parenchim şi dilatație bazinetală). Alterarea funcțională renală se corelează mai bine cu alterarea parenchimului renal decât cu dilataţia pielică. (Test Spearman - se consideră semnificativ statistic un $\mathrm{p}<0,05)$

\begin{tabular}{|c|c|c|}
\hline $\begin{array}{c}\text { Reducere parenchim } \\
\text { renal }<50 \%(n=21)\end{array}$ & $\begin{array}{c}\text { Funcție renală }<40 \% \\
(n=20)\end{array}$ & $p=0,00003$ \\
\hline $\begin{array}{c}\text { Diametru A-P bazinet } \\
>3 \mathrm{~cm}(\mathrm{n}=24)\end{array}$ & $\begin{array}{c}\text { Funcție renală }<40 \% \\
(\mathrm{n}=20)\end{array}$ & $\mathrm{p}=0,04172$ \\
\hline
\end{tabular}

(semnificativ statistic $p<0,05$ )

Indicația chirurgicală s-a stabilit în urma prezenței a 4 criterii în 6 cazuri, 3 criterii în 12 cazuri, 2 criterii în 18 cazuri şi a unui singur criteriu în 4 cazuri.

TABELUL 6. Numărul de criterii prezente în stabilirea indicației chirurgicale

\begin{tabular}{|c|c|c|}
\hline Nr. criterii & Nr. unități renale & Distribuție procentuală \\
\hline 1 & $\mathrm{n}=4$ & $10 \%$ \\
\hline 2 & $\mathrm{n}=18$ & $45 \%$ \\
\hline 3 & $\mathrm{n}=12$ & $30 \%$ \\
\hline 4 & $\mathrm{n}=6$ & $15 \%$ \\
\hline
\end{tabular}

Cea mai mare proporție o găsim corespunzător cazurilor ce au prezentat 2 criterii - $45 \%$, urmate de 3 criterii $-30 \%$, 4 criterii $-15 \%$.

Un singur criteriu prezent a fost identificat in cazul a 4 unități renale: 2 cazuri de obstrucție incompletă prin vas polar aberant, la care indicația a fost simptomatologia colicativă persistentă şi 1 pacient cu hidronefroză bilaterală, la care intervenția s-a bazat pe prezența dilatației bazinetale şi a distrucției parenchimatoase controlaterale (datorită bilateralității leziunii, funcția comparativă renală nu a fost utilizată drept criteriu).

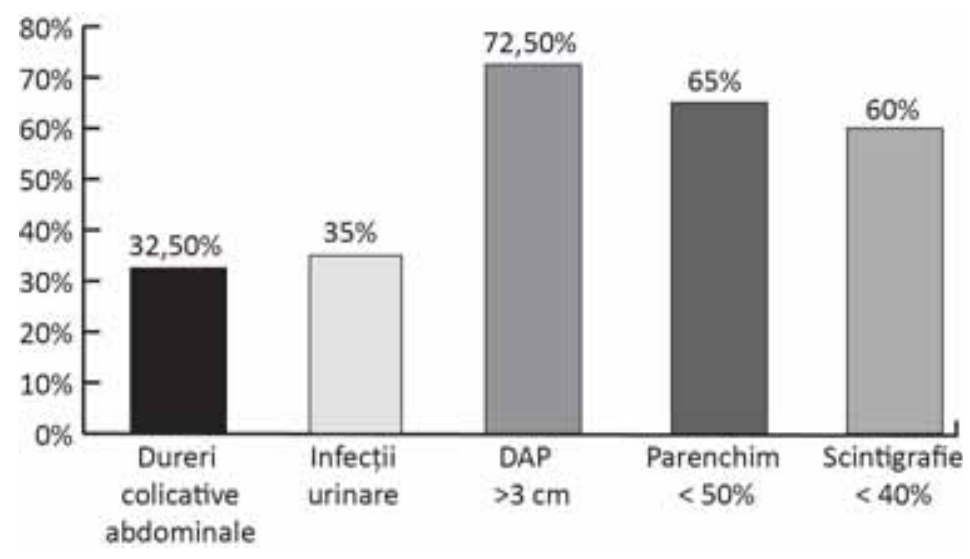

FIGURA 1. Incidența criteriilor indicației chirurgicale 


\section{DISCUȚII}

În indicaţia tratamentului chirurgical laparoscopic pentru hidronefroză la copil, vârsta mică (sub 1 an) şi greutatea redusă (sub $10 \mathrm{~kg}$ ) ale pacientului nu constituie o contraindicație sau un motiv de temporizare a tratamentului chirurgical. În lotul nostru, aceştia au fost reprezentați într-o proporție de $17,5 \%$, respectiv $22,5 \%$.

Un subgrup important este reprezentat de formele de obstrucție parțială a joncțiunii pielo-ureterale prin vas polar inferior. Indicația chirurgicală la aceşti pacienți este stabilită, cel mai adesea, în ciuda unei funcționalități renale normale şi a unui parenchim cu minimă afectare. Caracteristic acestor pacienți este prezența unei dilataţii semnificative bazinetale, cu valori oscilante care se corelează cu episoadele colicative lombare, apărute cel mai frecvent la copiii mari/adolescenți în contextul unei ingestii crescute de lichide. Scintigrafia evidențiază o curbă de tip obstructiv cu răspuns pozitiv la administrarea de diuretic.

Indicația chirurgicală a fost stabilită pe baza unui singur criteriu, în cazul durerilor lombare colicative recurente, secundare obstrucției extrinsece prin vascularizație aberantă şi în cazul hidronefrozei bilaterale. Numărul criteriilor prezente se corelează cu gravitatea afectării renale, astfel încât nu este necesară prezența tuturor criteriilor în stabilirea indicației chirurgicale. Elementele de maximă importanță în ceea ce priveşte gravitatea lezională şi potenţialul evolutiv sunt grosimea parenchimului renal şi funcționalitatea renală, între care există o puternică corelație.
Numitorul comun în afecțiunile urologice este reprezentat de dilatațiile căilor urinare, cel mai facil de cuantificat fiind diametrul bazinetului. Pielectazia este semnalul de alarmă şi punctul de plecare în evaluarea bolnavului hidronefrotic. Deşi acesta nu este specific sindromului de joncțiune pielo-ureterală, poate apărea în absența unei obstrucții şi nu prezintă întotdeauna o corelație puternică cu alterarea funcțiiei renale (3).

\section{CONCLUZII}

Deşi în literatură aparent nu există o cuantificare exactă a gradului dilatației ce prezintă indicație chirurgicală, elementele de bază în stabilirea conduitei terapeutice generale şi implicit a indicaţiei operatorii rămân: amploarea restructurărilor parenchimatoase renale, gradul afectării funcționalității renale şi simptomatologia clinică (4). Tratamentul laparoscopic este o soluție chirurgicală care întruneşte toate avantajele minim-invazivității, aplicabilă copiilor şi sugarilor, indiferent de vârstă şi greutate, cu mențiunea că necesită o dotare tehnică superioară şi experiență în tehnicile laparoscopice (5).

În cadrul nefropatiei obstructive secundare PUJO, tradusă la nivel histologic prin tubulopatia obstructivă, dozarea unor markeri urinari (factor de creştere epidermală - EGF), $\beta 2$ microglobulina $\beta 2 \mathrm{M})$ a deschis noi posibilităţi de cuantificare a afectării renale, cu posibilă utilitate în stabilirea indicației chirurgicale (6). În privința tratamentului minim-invaziv, pieloplastia robotică tinde să înlocuiască tehnicile laparoscopice, cu avantaje nete în special la copilul cu greutate mică $(7,8)$. 